\title{
Toward Conservation of Canada's Boreal Forest Avifauna: Design and Application of Ecological Models at Continental Extents
}

\section{Conservation de l'avifaune de la forêt boréale au Canada : élaboration et application de modèles écologiques à l'échelle continentale}

\author{
$\underline{\text { Steven G. Cumming }}^{1}, \underline{\text { Kara L. Lefevre }}^{1}{ }^{\text {Erin Bayne }}{ }^{2}, \underline{\text { Trish Fontaine }}^{3}$, Fiona K.A. Schmiegelow ${ }^{3}$, and \\ Samantha J. Song ${ }^{4}$
}

\begin{abstract}
Human development is increasing pressure on North America's mainly intact boreal forest. We outline the need for a comprehensive synthesis of existing data and for effective scientific tools to support conservation of this biome and of the birds that depend on it. To illustrate how broad collaborations can address these needs, we introduce and report on the Boreal Avian Modelling Project. This is a new partnership involving universities, government, private, and nongovernment groups that was created to develop spatially explicit, predictive models of boreal bird habitat associations across Canada. This initiative is designed to improve our understanding of the influence of environmental factors and human activities on boreal bird species, leading to spatially explicit predictive models of the distribution of avian populations. The intended applications of these models are land use planning and avian conservation across the nearctic boreal forest. In this essay, we present a description of the extensive collection of point count survey data assembled by the Project, and the library of spatial covariates used for modeling. We show how it is possible to account for a number of nuisance variables related to differences in survey protocol among source data sets and make some preliminary suggestions as to how future surveys could be standardized. We present a distance-sampling approach used to convert standardized point count data to density estimates, which we illustrate by providing habitat-specific densities and total population estimates for one species in a part of western Canada. We also illustrate the use of Classification and Regression Trees to develop species niche models from the standardized data. We conclude with a discussion of the need for a monitoring program for boreal birds in Canada, the role of predictive statistical models in developing such a program, and how monitoring could be related to boreal bird conservation through adaptive management.
\end{abstract}

RÉSUMÉ. Le développement humain exerce une pression croissante sur la forêt boréale de l'Amérique du Nord, en bonne partie intacte. Nous exposons brièvement les raisons pour lesquelles il est essentiel de faire une synthèse détaillée des données existantes et de mettre au point des outils scientifiques efficaces si on veut promouvoir la conservation de ce biome et des oiseaux qui en dépendent. Afin d'illustrer de quelle façon des collaborations élargies peuvent répondre à ce besoin, nous présentons le Projet de modélisation de l'avifaune boréale (PMAB). Le PMAB, récent partenariat entre les universités, les gouvernements et les groupes non gouvernementaux, a été créé dans le but d'élaborer des modèles de prévision, explicites spatialement, sur les associations entre les oiseaux boréaux et leurs milieux dans l'ensemble du Canada. Cette initiative a été conçue dans le but d'améliorer notre compréhension de l'effet des facteurs environnementaux et des activités humaines sur les espèces d'oiseaux boréaux, au moyen de modèles de prévision de la répartition des populations aviaires. Ces modèles sont destinés à la planification de l'utilisation du sol et à la conservation des oiseaux dans l'ensemble de la forêt boréale néarctique. Cet essai présente une description de l'imposante base de données assemblée par le PMAB (les données

\footnotetext{
${ }^{1}$ Département des sciences du bois et de la forêt, Université Laval,

${ }^{2}$ Department of Biological Sciences, University of Alberta, ${ }^{3}$ Department of Renewable Resources, University of Alberta, ${ }^{4}$ Canadian Wildlife Service,

Environment Canada
}

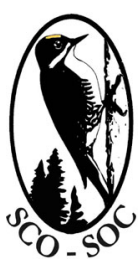

Sponsored by the Society of Canadian Ornithologists and Bird Studies Canada Parrainée par la Société des ornithologistes du Canada et Études d'oiseaux Canada

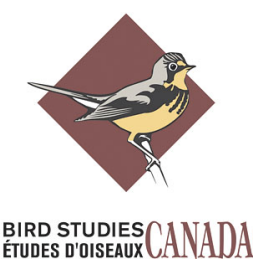


proviennent de dénombrements par points d'écoute), de même que le répertoire des covariables spatiales utilisées pour la modélisation. Nous montrons qu'il est possible d'estimer les variables «problématiques», c.-à-d. les variables relatives aux différences dans les protocoles d'inventaire des diverses bases de données source, et faisons quelques suggestions préliminaires quant à la normalisation des futurs relevés. Nous présentons l'approche fondée sur la distance que nous avons utilisée pour convertir des données de points d'écoute normalisées en des estimations de densité; nous illustrons cette approche à partir des densités spécifiques à l'habitat et de l'estimation de l'ensemble de la population d'une espèce occupant une partie de l'ouest du Canada. Nous décrivons également l'emploi des arbres de classification et de régression pour élaborer des modèles de niches d'espèces à partir des données normalisées. Nous concluons par une discussion au sujet de la nécessité de mettre en place un suivi des oiseaux boréaux du Canada, du rôle des modèles de prévision statistique dans l'élaboration d'un suivi de ce genre, et enfin, de la façon avec laquelle ce suivi pourrait être lié à la conservation des oiseaux boréaux grâce à la gestion évolutive.

Key Words: boreal forest; Breeding Bird Survey; Classification and Regression Trees; conservation planning; distance sampling; habitat models; land use; migratory birds; point counts; population management; scale; species distributions; survey methods.

\section{INTRODUCTION}

Comprehensive avian conservation is necessary because of the spatially extensive changes to habitat resulting from industrial activity and climate warming. These processes have affected, or may in the future affect, much or all of the breeding ranges of boreal birds. Effective planning requires quantitative, predictive relationships between ecological patterns and processes at local, regional, continental, or even larger extents (Kerr et al. 2007, Peters et al. 2008). Historical approaches to bird research and management have concentrated on single species or simple community-level metrics measured over small areas (Freemark et al. 1995). There is a need to bridge the gap between the scales of traditional research and emerging conservation needs in the boreal regions of Canada.

Canada's boreal forest sustains a large share of North America's avifauna. The are $>200$ terrestrial bird species that breed there, representing almost a third of the species found north of Mexico (Blancher 2003, Berlanga et al. 2010). Most species are migratory, which poses unique management challenges because they are influenced by ecological conditions that span continents (Webster et al. 2002, Martin et al. 2007). Populations of transboundary species can serve as indicators of ecological responses across diverse and distant landscapes (Roca et al. 1996). In addition to their inherent ecological importance to boreal ecosystems, Canada's boreal bird populations represent an opportunity for macroscale approaches to conservation based on the quantitative understanding of species distributions and abundances.

Compared to other Nordic regions, Canada's boreal forest remains relatively undeveloped (Ostlund et al. 1997, Lee et al. 2003). It retains immense pristine areas large enough to be structured by natural ecosystem processes, such as wildfire and insect outbreaks (Hansson 1992, Krawchuk et al. 2006). The boreal forests of Canada present unparalleled opportunities for proactive conservation planning, but these opportunities are time-sensitive: the rate and extent of industrial development in the boreal region has increased sharply in recent decades (Fig. 1), leading to the rapid transformation of large areas (Hobson et al. 2002, Schneider et al. 2003; Fig. 2). These developments have inspired many local studies of avian habitat relationships that have increased both scientific knowledge and significant new datasets that could inform boreal conservation at a national scale. In this essay, we introduce the Boreal Avian Modelling Project (BAM; http://www .borealbirds.ca/), a coordinated cross-scale research effort designed to help realize this opportunity. We illustrate some applications of this research with new results on the regional density of the Ovenbird (Seiurus aurocapilla) and the boreal-wide distribution and abundance of the Black-throated Green Warbler (Dendroica virens). We conclude with a discussion of applications to the design of future sampling and monitoring programs in the context of adaptive management. 
Fig. 1. The Canadian boreal forest faces growing threats from human activity, as illustrated by this time series of aerial photographs from the Swan Hills in west-central Alberta. The region was essentially wilderness circa 1950 (top left). As early as 1964 (top right), numerous well pads had been constructed for extracting natural gas, connected by a network of gravel roads and pipeline corridors. These developments were preceded by the construction of a network of narrow $(5-8 \mathrm{~m})$ seismic lines used for exploration seismology, which are visible as faint straight lines in the image. By the early 1980s (bottom left) forest harvesting had been added to these earlier disturbances, together with expansion of the primary road network. All these developments intensified over the following decade (bottom right), a process which continues to this day. Photos were reproduced with permission from "Alberta Sustainable Resource Development, Air Photo Distribution". Images are protected under the Copyright Act of Canada.

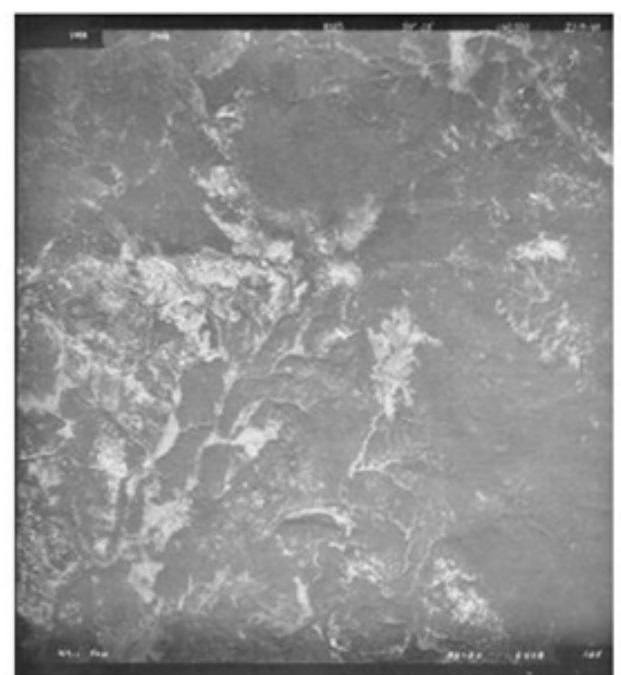

Photo taken 1949

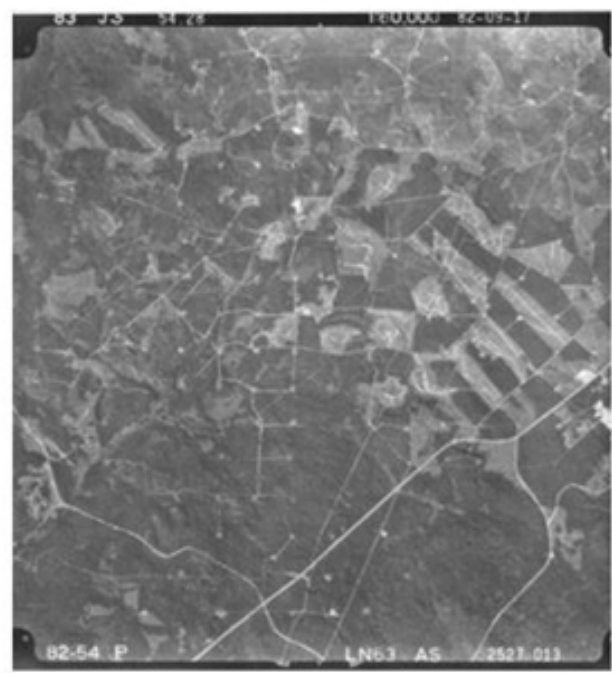

Photo taken 1982

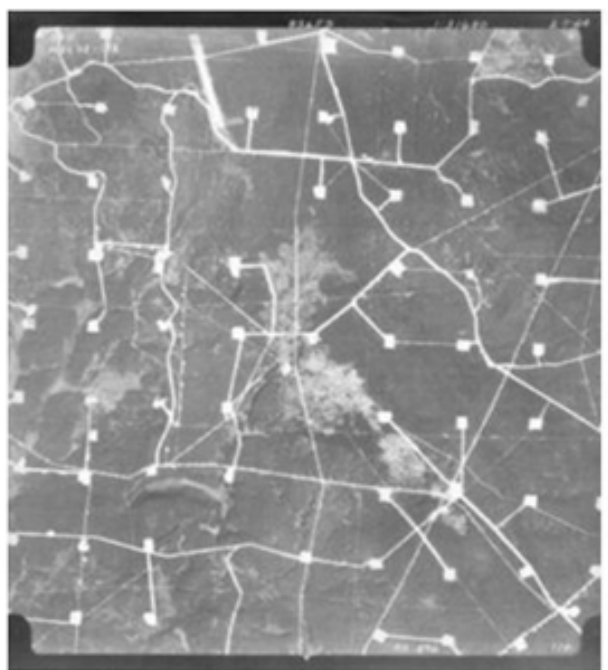

Photo taken 1964

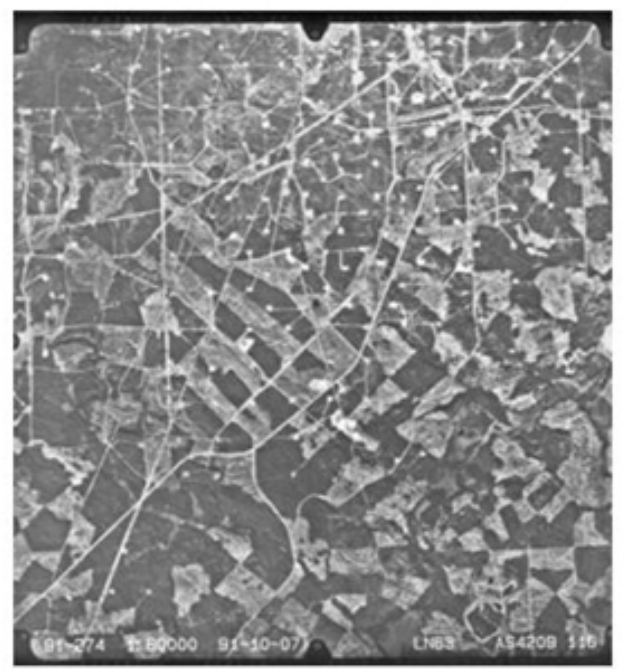

Photo taken 1991

(c) Alberta Environment 1996. Compled by Richard Thomas 1996. 
Fig. 2. Local changes such as seen in Figure 1 are occurring in varying degrees across very large areas of the Canadian boreal, including this region of the boreal plains ecozone in Saskatchewan and Manitoba. The areas labelled "Anthropogenic change" are alterations to natural forest cover over the period 1990 to 2000. The areas coloured in yellow (Treeless area) would for the most part have been forested prior to European settlement, but have since been converted to agricultural land use, a process that continues to this day (Hobson et al. 2002).

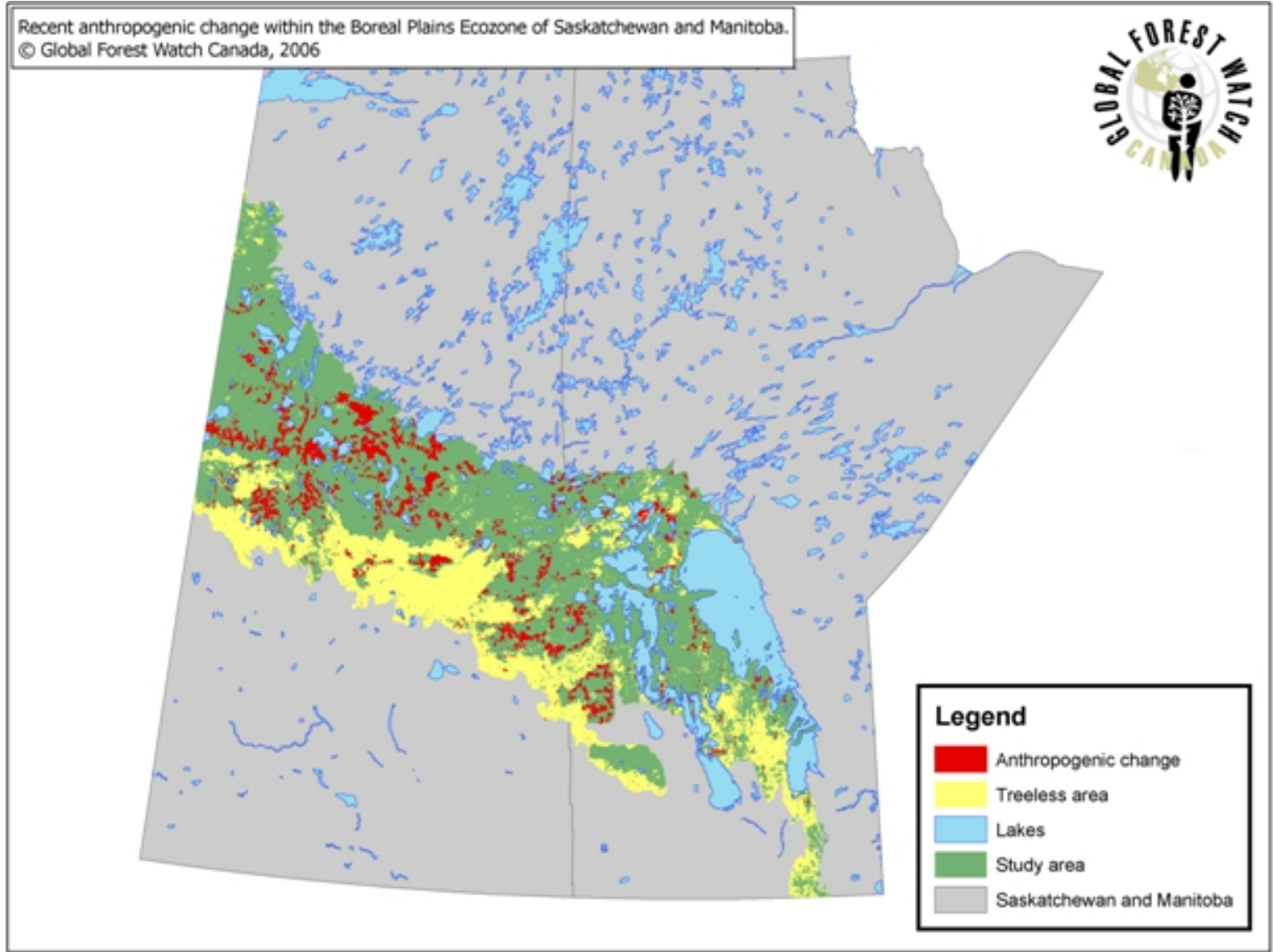

\section{CROSS-SCALE CHALLENGES FOR MODELING AND MANAGING BOREAL BIRD POPULATIONS}

Responsibility for bird conservation in North America is distributed across many levels of government, including federal, state, territorial, and provincial jurisdictions. A cooperative approach is enshrined in Canada's Migratory Birds Convention Act 1994 (MBCA), manifested by participation in the North American Bird Conservation Initiative and by adoption of Bird Conservation Regions, the basis for bird conservation planning across the continent (Cooke 2003, Rich et al. 2004). To be effective, these efforts must integrate local management actions with ecologically relevant outcomes measured at regional and continental levels. This requires a quantitative understanding of the larger scale processes affecting species distributions and abundances.

Local ornithological studies have been integral to revealing bird species-habitat associations (Jones 2001). Decades of such research have clarified how vegetation composition and structure influence bird distributions, abundances, and community composition (Willson 1974, Anderson 1981, Cody 1985, Urban and Smith 1989, Lichstein et al. 2002). However, 
local studies must be generalized to large spatial extents if they are to be useful for forest management and avian conservation. For example, when setting priorities for species conservation within a particular forest tenure area or jurisdiction, it would be helpful to know what proportion of total species breeding populations might be affected by management actions in the area. These proportions cannot be determined by any local study.

There is growing interest in the analysis of spatially extensive data to support regional, national, and continental conservation planning (Forcey et al. 2007, Thogmartin and Knutson 2007). Predictive habitat models are an important tool for this approach (Guisan and Zimmermann 2000, Rushton et al. 2004, Austin 2007). Such models regress species distribution or abundance data against suites of biophysical covariates to relate the locations of organisms to their environments (Guisan and Zimmermann 2000). As spatial extent increases, modeling becomes more difficult because distributions are affected by vegetation as well as variation in landscape structure and climatic or other abiotic variables (Luoto et al. 2004). Recent studies have explored these relationships regionally (Flather and Sauer 1996, Fauth et al. 2000, Heikkinen et al. 2004, Venier et al. 2004, Fearer et al. 2007, Forcey et al. 2007, Thogmartin and Knutson 2007). There have been fewer studies at continental or similar extents (but see Thuiller et al. 2004, Rahbek et al. 2007, Buermann et al. 2008), in part because obtaining data is difficult. Collectively, this research affirms that avian habitat selection occurs at many spatial scales, from the nest to the continental (Donovan et al. 2002). To disentangle the causal factors influencing birds across scales requires predictive habitat modeling at multiple resolutions and large extents (Donovan et al. 2002, Luoto et al. 2004).

Overall, the distributions and abundances of boreal birds are not well documented. Most extensive analyses of land bird distributions have been based on the North American Breeding Bird Survey (BBS; Venier et al. 2004, Fearer et al. 2007, Forcey et al. 2007, Thogmartin and Knutson 2007) or on atlas programs (Gates et al. 1994, Gregory and Gaston 2000, Devictor et al. 2008). Among the relatively few such studies in the Canadian boreal region, Cumming et al. (2001) used BBS route data to detect population declines along the interface between boreal forest and agricultural lands, while Venier et al. (2004) used BBS data to discern the relative importance of climate and land cover. However, BBS and atlas data are both constrained by accessibility, primarily by road networks which are sparse or absent in much of the boreal region. Management and conservation of boreal bird populations requires better baseline information than can be provided by BBS or atlas data. Fortunately, alternate sources of avian data exist that are less dependent on road networks and that also improve upon the spatial coverage or resolution provided by boreal BBS and atlas data.

Although boreal data coverage remains incomplete, statistical habitat modeling can effectively interpolate sparse data to inform conservation and management over large, under-sampled, remote regions (Gottschalk et al. 2005). Many of the data sets under discussion were specifically assembled to support local habitat modeling projects (e.g., Drapeau et al. 2000, Machtans 2006, Rempel et al. 2007, Vernier et al. 2008). However, these data are distributed amongst numerous disparate studies that are confined largely to the southern parts of the biome (Schmiegelow and Monkkonen 2002, Blancher 2003). More serious are methodological differences among studies. These differences have severely limited our ability to apply and generalize the findings of individual projects by synthetic or meta-analytical techniques (e.g., Schieck and Song 2006). It has therefore been difficult to draw conclusions about the influence of local versus regional variation in environmental attributes or to address possible geographic differences in habitat selection.

Despite these challenges of data coverage, ownership and consistency, we believe that modelbased approaches are possible in the Canadian boreal forest. They are also essential to developing a better baseline understanding of boreal bird distributions, given the lack of monitoring data. Predictive habitat models can synthesize existing information and, by incorporating multiple sources of observational data, reveal biome-wide patterns not evident in individual studies. If these models are constructed and evaluated using robust methods, they could be applied across larger, unsampled, regions of interest (Vernier et al. 2008) as a means of making the best use of available data and for generating testable hypotheses regarding underlying mechanisms influencing bird abundance and distribution. 


\section{AVIAN HABITAT MODELING ACROSS THE BOREAL FOREST OF CANADA}

The amount and geographic scope of bird research in the Canadian boreal forest has increased markedly since the 1990s (Schmiegelow et al. 1997, Drapeau et al. 2000, Hobson and Bayne 2000, Machtans 2006, Schieck and Song 2006, Rempel et al. 2007, Venier and Pearce 2007, Vernier et al. 2008). A systematic compilation and analysis of information contained in these studies presents our best opportunity to understand the drivers of avian distribution and abundance in the boreal forest and to inform conservation planning. BAM was established to capitalize on this opportunity by: 1) compiling as much existing data as possible; 2) applying consistent analytical approaches to contributed data; and 3) modeling bird distributions and abundances across the region. Our modeling aims are descriptive, predictive, and explanatory. We wish to accurately describe the current distributions and abundances of boreal species, to quantify macro- and patch-level habitat selection, and to improve estimates of population size. Our goal is to predict the consequences for boreal avifauna of management actions, land use decisions, and climate change and thereby contribute to the design of effective conservation plans. We also plan to use the data and models to formulate and test ecological hypotheses about the determinants of species distributions, range limits, variation in species' habitat selection across the boreal forest, and the structure of boreal bird communities. In the long term, we expect our results to encourage the standardization of point count sampling protocols in Canada and to contribute to the design of monitoring programs.

Much of the currently available data come from point count surveys, which quantify birds that are seen or heard within a specified distance of a fixed location over short intervals (Ralph et al. 1995). Point counts provide a reasonable index of songbird abundances in boreal forest (Toms et al. 2006) and are among the most standardized of surveys methods. When sampled in undisturbed habitats, e.g., distant from roads or similar features, they should also provide more reliable abundance indices for birds using interior forest habitat than the BBS or other roadside surveys can. Although BBS data are a form of point count surveys, we have found that the data from Canadian boreal routes can suffer from marked roadside bias, underestimating abundances or, in some cases, essentially failing to detect forest species that are in fact abundant in nearby habitats. We will present an example of this. Datasets collected away from roads have therefore been our focus.

Thanks to the generosity and good will of our partners from academia, governmental and nongovernmental agencies, and the private sector, we have assembled a comprehensive database of spatially referenced point count data (Table 1) from across the Canadian boreal forest (Fig. 3). The raw point count data from the 88 contributing projects were obtained from the owners under data-sharing agreements specific to this project. After standardizing species codes, geographic coordinates, sampling dates and times, and many other factors, the individual components were integrated into a relational database using Microsoft Access. The structure of the database, the encoding of the specifics of sampling protocols among projects, and some aspects of the spatial and temporal distribution of sampling effort are fully described in an online report (Cumming et al. 2010a). Producing an equivalent data set through targeted fieldwork would be prohibitively expensive, if not impossible. We intend this database to be the foundation for descriptive and statistical analyses of boreal land bird distribution and abundance, to provide the baseline data for future sampling efforts in the boreal, and to become the natural data repository for such future studies.

The details of survey protocols vary among projects in important ways that affect bird counts (Alldredge et al. 2007). For example, the survey duration and estimated sampling radius differ among contributed studies. The majority of studies spanned one breeding season but collectively, they cover almost 20 years (Fig. 4), so data are affected by annual changes in weather, resource availability, local habitat characteristics, and observer identity. The time and date of sampling also vary within studies such that the diurnal and seasonal patterns of singing behavior and settlement markedly affect bird presence and detectability and, hence, the observed counts. Such differences pose significant analytical challenges.

We have been able to address some of these "nuisance factors." Species-specific correction factors were developed for the effects of sampling duration, distance, time of day, and date of year. For 
Table 1. The size of the Boreal Avian Modelling Project database as of February 2009, as measured by numbers of contributors, surveys and survey locations, and individual detections.

\begin{tabular}{lc}
\hline \hline Measure & Total \\
\hline Bird data partners (contributors) & 53 \\
Research projects & 88 \\
Surveyed locations & 37,100 \\
Surveys conducted $\dagger$ & 75,846 \\
Birds detected & 581,806 \\
\hline
\end{tabular}

$\dagger$ includes multiple visits to the same location within a single year or over multiple years.

example, in the case of sampling time and distance, we used subsamples of data from studies that had stratified observations into distance and time classes (e.g., 0-3 min, 3-5 min, and 5-10 min) to estimate correction factors relative to a chosen standard (10 minute, unlimited distance). We hope that this work, to be reported elsewhere, will encourage standardization of future point count survey protocols (e.g., Carlson and Schmiegelow 2002). We suggest that point count observations should be recorded in at least two time and two distance classes to permit estimation of detectability by distance sampling methods. Finer resolution, e.g., recording observations by 1 minute intervals, may be better up to some limit determined by the inevitable tradeoff between field effort and reliability. However, two classes are sufficient to model some aspects of detectability and to fit the simplest oneparameter distance functions. One can then develop estimators of species densities from point count data. Such estimators are necessary if we are to reliably predict future bird populations and identify species most at risk, whether locally, regionally, or nationally.

We have assembled a catalogue of spatial environmental covariates for statistical modeling of the avian data. Covariates were selected a priori to include examples of all factors known or expected to affect macroscale avian distributions, subject to data availability at national extents. All are independent of the avian survey data. The datasets are described in detail in Cumming and Leblanc
$(2010 a, b)$ and on the BAM website. The covariates include: $30 \mathrm{yr}$ (1971-2000) means and standard deviations of monthly temperatures and precipitation; leaf area indices and land cover derived from multispectral remote-sensed data; cartographic data, e.g., hydrology and land use; and disturbance history, e.g., fire and forest harvesting. Remotesensed covariates are all publicly available products derived from Moderate Resolution Imaging Spectr oradiometer (MODIS) or SPOT imagery. Our land cover model is derived from the $250 \mathrm{~m}$ resolution Land Cover Map of Canada 2005 (LCC05; Latifovic et al. 2008). The legend for this MODISbased product defined 39 habitat types, which we reclassified down to 17 types (Table 2).

\section{Density and population estimates}

Past studies of boreal birds relied almost entirely on relative abundance to identify local habitat preferences, so regional comparisons via literature review provide qualitative descriptions of habitat selection that scarcely advance the ability to set population targets. More recent efforts have used repeated measures and/or distance-based sampling to convert relative abundance into the density estimates that are needed for inter-regional comparisons and population estimates (Thompson 2002). Our approach to accounting for nuisance factors enables an alternate method of density estimation that is capable of producing credible and testable predictions of future distribution and 
Fig. 3. The Canadian boreal forest and taiga regions as defined by The Boreal Avian Modelling Project. The locations of point count survey data assembled as of February 2009 are indicated with black dots.

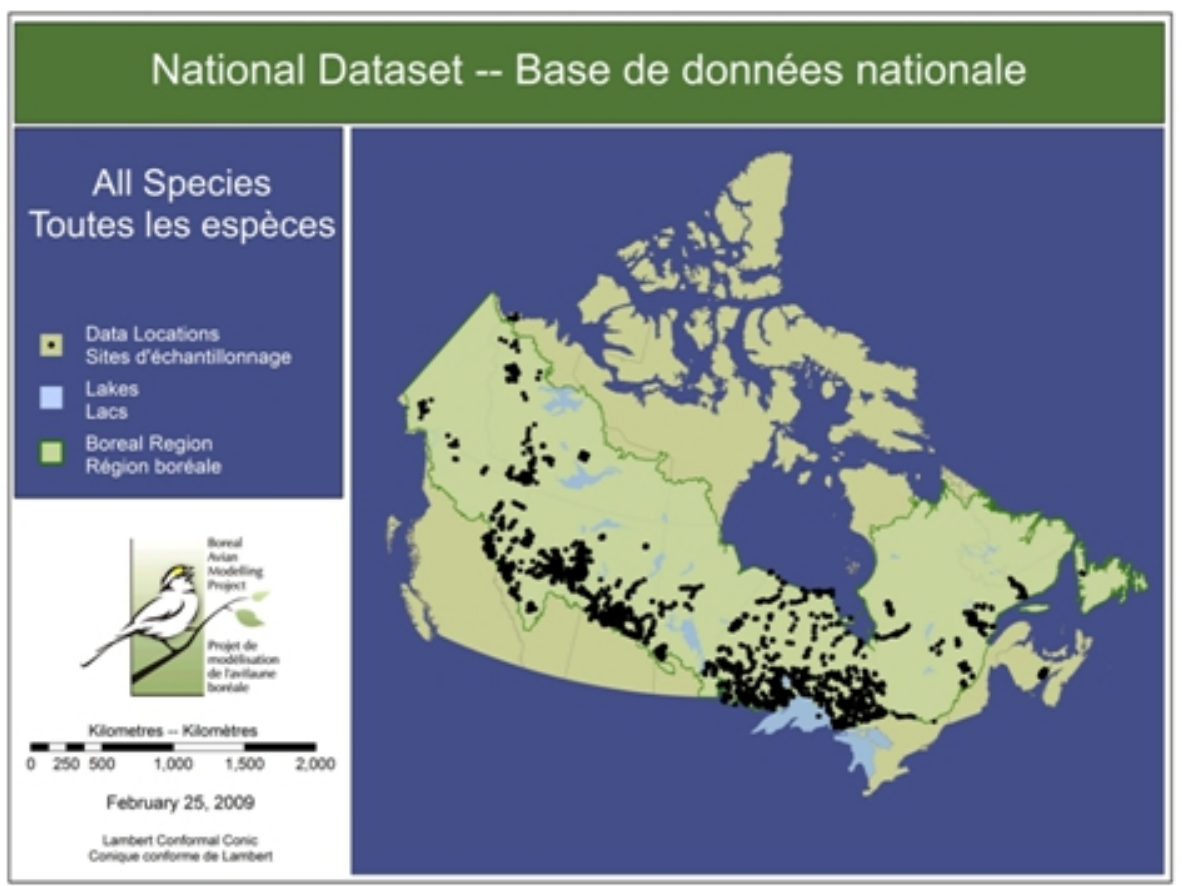

abundance patterns under a complex range of management, land use and climate change scenarios. We have applied this method using spatially stratified counts and remotely sensed vegetation data across Canada, to estimate strataand habitat-specific mean densities for many species. This has led to new and, we believe, improved population estimates that are relevant for migratory bird management efforts, for example, through Bird Conservation Regions plans for boreal Canada (Environment Canada 2010). To illustrate, we report habitat class specific density estimates and boreal population estimates for the Ovenbird. We used Bird Conservation Regions (BCRs; NABCI 2000) and provincial/territorial jurisdictional units as our spatial stratification, and the habitat classes of Table 2 .

Table 3 shows the mean count for male Ovenbirds by habitat class (Table 2) with $95 \%$ confidence intervals using data from the part of BCR 6 (Boreal Taiga Plains) within the Province of Saskatchewan. We used a mixed-effects Poisson regression model to correct for the nuisance factors described above.
The contributing projects used different survey protocols and were published using various analytical techniques. The model specification was such that means were normalized to a standard survey protocol; in this case, a 10-minute point count with unlimited sampling radius.

While standardizing counts will improve our ability to describe relative patterns of habitat suitability within species, there is also a need to develop estimates of absolute densities. With these, we could estimate population sizes and make absolute comparisons between the effects of different types of activities over different scales. Given an appropriate estimate of the effective sampling radius, $r$, mean counts may be converted to densities in individuals per hectare, by dividing by $\pi r$ $2 / 10,000$. Partners in Flight (Blancher et al. 2007) used the maximum distance heard as the sampling radius. For the Ovenbird, they report $r=200 \mathrm{~m}$ but strongly encouraged validation of these radii.

We have developed new estimates of sampling radii based on distance sampling using the half-normal 
Fig. 4. The temporal distribution of sampling effort in the Boreal Avian Modelling Project's avian database, as of 25 February 2009.

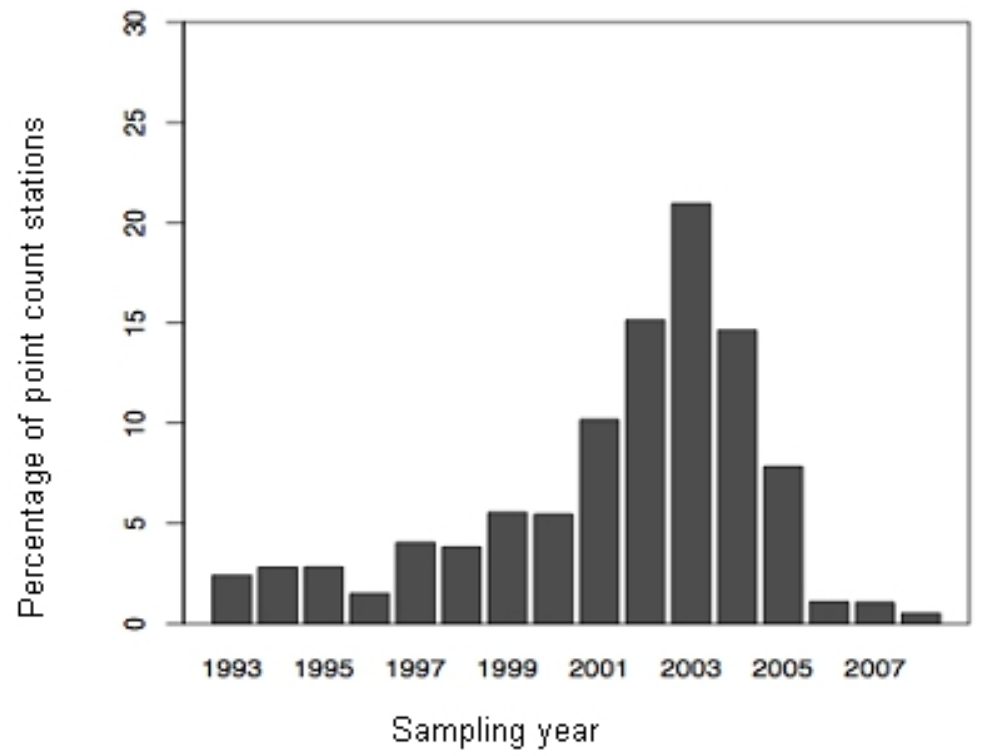

binomial estimator (Buckland et al. 2001). This is one of the simplest statistical models of the decay of detection probability with distance from observer. One advantage of this model is that precise distances for each observation are not required. The model can be fit using data from only two distance classes. About $50 \%$ of BAM's data was collected under protocols that recorded at least two distance classes. We used those data where observations could be stratified as detections at distances of less than or greater than $50 \mathrm{~m}$. Using these two classes, the half-normal binomial estimator yields an effective detection radius (EDR) that can be used as the value of $r$ when converting counts to densities. In the case of the Ovenbird, this distance is $84 \mathrm{~m}$. Table 3 shows the adjusted count data converted to estimated densities using the two approaches.

Ovenbird density estimates calculated using the EDR are 5.7 times greater than when using the Partners in Flight method based on maximum detection distance (Blancher et al. 2007). Determining which of these two values is closer to the truth requires further research. However, we can provide partial support for our approach based on Bayne and Hobson (2002), who conducted intensive color-banding and territory mapping within the part of Saskatchewan referenced in Table 3. They found the mean density of male Ovenbirds in mature aspen forest and aspen-dominated mixed woods was 0.99 males per hectare. According to the results of BAM's analysis, the highest mean Ovenbird count was 0.174 , in habitat class "Closed Deciduous Mixed" (Table 3). The corresponding EDR-based density estimate was 1.008 male Ovenbirds per hectare. Based on the original LCC05 legend (Latifovic et al. 2008), our "Closed Deciduous Mixed" habitat class is probably the closest approximation among our remote-sensed habitat classes to the real habitats sampled by Bayne and Hobson (2002). Thus, at least for this species and region, the EDR-based density estimates correspond closely to the results of detailed field measurements in equivalent habitats. On our website, we present EDR-based density estimates for many boreal passerines at the scale of provincial/territorial jurisdictions within BCRs.

Current estimates of passerine populations across North America (Blancher et al. 2007) are based on BBS counts and corrected to abundances by the methods described by Partners in Flight. As noted, these estimates are sensitive to the assumed sampling radius and may have limitations for forest 
Table 2. The habitat classification used by Boreal Avian Modelling Project, based on a reclassification of the Land Cover Map of Canada 2005 (LCC05; Latifovic et al. 2008). The published legend contained 39 labels (LCC05 Labels). These were reclassified to 17 classes (BAM Class Name and Code) based on representation within the BAM sample (Fig. 3), geographic distribution, similarity within the hierarchical legend, and estimated mean abundances of three widely distributed bird species.

\begin{tabular}{lll}
\hline \hline BAM Class Name & BAM Code & LCC05 Labels \\
\hline Closed Coniferous & 1 & 1 \\
Closed Deciduous & 2 & 2 \\
Closed Mature Mixed & 3 & 3 \\
Closed Young Mixed & 4 & 4 \\
Closed Deciduous Mixed & 5 & 5 \\
Open Coniferous & 6 & 6,7 \\
Sparse Coniferous & 8 & $8,13,20$ \\
Sparse Coniferous Shield & 9 & 9 \\
Poorly Drained & 10 & 10,19 \\
Open Mature Deciduous & 11 & 11 \\
Open Young Deciduous & 12 & 12,16 \\
Open Mixed & 14 & 14 \\
Open Young Mixed & 15 & 15 \\
Open Herb/Grass & 17 & 17,18 \\
Open Northern & 21 & $21,22,23,24,25,30,31,32$ \\
Mixed Forest/Crop & 26 & $26,27,28,29$ \\
Burns & 33 & $33,34,35$ \\
Not used & & $36,37,38,39$ \\
\hline
\end{tabular}

species and for remote areas, resulting in biased estimates of species counts. By combining data from multiple forest interior studies, as we have done, it is possible to compare "interior" point counts to counts from road based surveys. Using off-road data from the Canadian portions of BCR's $4,6,8,10$, and 12, we estimated Ovenbird population size for the boreal forest of Canada using Partners in Flights' maximum distance heard as a sampling radius. The resulting estimate was $\sim 28$ million breeding
Ovenbirds, males and females, in these Canadian BCRs; note that our estimate using EDR would be almost six times larger. Using data from on-road locations only, the official Partners in Flight estimate for the entire North American continent is $\sim 24$ million. This suggests that on- versus off-road data can have a very strong influence on estimates of bird population sizes, a topic for future research within BAM. These findings also suggest that current BBS data are insufficient for understanding 
Table 3. Density of Ovenbirds (males per hectare) in BCR 6 in the province of Saskatchewan. Data are stratified by MODIS habitat class reclassified into 17 major types. "Mean Count" is the estimated mean number of males detected by a 10 minute unlimited distance point count within the habitat. "Density PIF" is the density estimate generated by dividing the mean count by the area sampled assuming a detection radius of 200m. "Density EDR" is the density estimate generated when our estimates of effective detection radius are used, based on distance sampling with a binomial half-normal estimator. The three main results are accompanied by the estimated $95 \%$ confidence intervals.

\begin{tabular}{lccccccccc}
\hline \hline Habitat & $\begin{array}{c}\text { Mean } \\
\text { Count }\end{array}$ & Lower95 & Upper95 & $\begin{array}{c}\text { Density } \\
\text { PIF }\end{array}$ & Lower95 & Upper95 & $\begin{array}{c}\text { Density } \\
\text { EDR }\end{array}$ & Lower95 & Upper95 \\
\hline Closed Conifer & 0.636 & 0.521 & 0.752 & 0.051 & 0.041 & 0.060 & 0.294 & 0.241 & 0.347 \\
Closed Deciduous & 1.637 & 0.900 & 2.374 & 0.130 & 0.072 & 0.189 & 0.757 & 0.416 & 1.097 \\
Closed Mature Mixed & 1.577 & 1.409 & 1.746 & 0.126 & 0.112 & 0.139 & 0.729 & 0.651 & 0.807 \\
Closed Young Mixed & 1.469 & 1.234 & 1.704 & 0.117 & 0.098 & 0.136 & 0.679 & 0.570 & 0.787 \\
Closed Decid. Mixed & 2.181 & 1.887 & 2.474 & 0.174 & 0.150 & 0.197 & 1.008 & 0.872 & 1.143 \\
Open Conifer & 0.741 & 0.649 & 0.834 & 0.059 & 0.052 & 0.066 & 0.343 & 0.300 & 0.385 \\
Sparse Conifer & 0.325 & 0.195 & 0.455 & 0.026 & 0.016 & 0.036 & 0.150 & 0.090 & 0.210 \\
Sparse Conifer Shield & 0.772 & 0.554 & 0.989 & 0.061 & 0.044 & 0.079 & 0.357 & 0.256 & 0.457 \\
Poorly Drained & 0.684 & 0.341 & 1.027 & 0.054 & 0.027 & 0.082 & 0.316 & 0.157 & 0.474 \\
Open Mature Decid. & 1.757 & 1.578 & 1.936 & 0.140 & 0.126 & 0.154 & 0.812 & 0.729 & 0.895 \\
Open Young Decid. & 0.855 & 0.743 & 0.966 & 0.068 & 0.059 & 0.077 & 0.395 & 0.344 & 0.447 \\
Open Mixed & 1.940 & 1.408 & 2.471 & 0.154 & 0.112 & 0.197 & 0.896 & 0.651 & 1.142 \\
Open Young Mixed & 0.735 & 0.599 & 0.872 & 0.059 & 0.048 & 0.069 & 0.340 & 0.277 & 0.403 \\
Open Herb/Grass & 0.934 & 0.791 & 1.077 & 0.074 & 0.063 & 0.086 & 0.432 & 0.365 & 0.498 \\
Open Northern & 0.616 & 0.390 & 0.841 & 0.049 & 0.031 & 0.067 & 0.285 & 0.180 & 0.389 \\
Mixed Forest/ Crop & 0.302 & 0.275 & 0.328 & 0.024 & 0.022 & 0.026 & 0.139 & 0.127 & 0.152 \\
Burns & 0.107 & -0.053 & 0.267 & 0.009 & -0.004 & 0.021 & 0.049 & -0.024 & 0.123 \\
\hline
\end{tabular}

the distribution and abundance of birds within the vast boreal biomes.

\section{Potential niches}

Our first comprehensive modeling efforts sought to identify species' potential habitat niches, that is, the biophysical envelopes within which species can potentially occur. We used classification and regression trees (CARTs; De'ath and Fabricius 2000) for this purpose. CART models were developed for approximately 100 species. The models can be converted into predictive maps of relative abundances over the entire boreal region. Candidate explanatory variables included our entire catalogue of environmental covariates. The response variables were observed counts at the point 
count station level. Multiple visits to individual stations were treated as independent for the time being. Our correction factors for sampling protocol, date, and time were included as offsets. This had the effect of standardizing predicted means to a 10minute unlimited distance point count conducted at the optimal time of day and date within the breeding season. In aggregate, these models have identified a reduced suite of key covariates for use in more complex statistical models. The detailed structure of the regression trees also enables us to test or formulate hypotheses about the relative importance of climate versus land cover in controlling largescale distributional patterns. Our models provide the first data-driven estimates of land bird distributions and populations across the Canadian boreal region.

The CART models will be available on the project website and will be fully described in a forthcoming manuscript. Here, we present a model for one species, the Black-throated Green Warbler (BTNW). This wood-warbler is widely distributed in the southern parts of the boreal region east of the continental divide (Fig. 5). The current version of the database recorded observations of 9086 individuals with a station-level prevalence of $12 \%$. The model (Fig.6) explained $53.5 \%$ of the deviance. The variables included in the model were: means of September and June Normalized Difference Vegetation Index (NDVI) calculated over the period 1998 through 2005; seasonality, i.e., the coefficient of variation of monthly mean temperatures; mean September temperature; and the standard deviation (SD) of July precipitation. The model partitions the observations into seven groups based on combinations of the levels of these covariates, and can be applied to produce a predictive abundance map (Fig. 7). We estimated the prediction reliability of each group in all CART models, adapting the methods of Kuhnert and Mengersen (2003). The reliabilities for the Black-throated Green Warbler model (Fig 8.) are very high for areas with low predicted abundance, which are found primarily in northern portions of the range. We interpret this as evidence that the northern boundary of the species range is adequately described by the climatic factors included in the model. The three terminal nodes with highest mean abundance have quite low reliabilities, even though these are mapped within areas where the species was observed to occur (Fig. 3 and Nodes 5, 6, 7 in Fig. 6). The low reliabilities indicate that the model does not fully explain variation in abundance among locations within these groups. In other words, the data within these groups are overdispersed. We attribute this to missing variables in the model. At least in the western boreal, the Blackthroated Green Warbler strongly selects for old deciduous dominated mixed wood forest (Vernier et al. 2008, Appendix 1). This habitat type is not reliably distinguished by the remote-sensed land cover covariates that were available when the CART models were fit. In addition, the Blackthroated Green Warbler is sensitive to forest habitat composition at scales of at least 81 ha (Vernier et al. 2008), whereas the spatial resolution of the land cover covariates used here was only 6 ha. Thus, within the bioclimatic envelope of high Blackthroated Green Warbler abundance, there exists high-frequency spatial variation in habitat characteristics that our present models do not capture.

The next step in BAM analysis will use hierarchical generalized linear models (e.g., Thogmartin and Knutson 2007). These can accommodate the spatialtemporal dependencies in our data and will allow us to model detectability effects directly (e.g., Royle et al. 2007). We will also seek to improve model sensitivity to the details of forest habitat structure and land use history. It is possible that such factors are just relatively unimportant at national extents, but we consider it more likely that the CARTs failed to detect such effects because the appropriate covariates were not available. Thus, the next generation of models will include high resolution habitat structure covariates. Variable selection among this much richer set of covariates will be facilitated in two ways. Preliminary analysis of our full suite of CART models showed that 13 of 131 available covariates accounted for $50 \%$ of the total deviance observed. Further analysis is expected to identify still smaller subsets of these 13 covariates that account for climatic and productivity effects at the level of migratory guilds or other species groups. From past experience in modeling avian habitat selection at local and regional levels using high resolution vegetation data (e.g., Vernier et al. 2008), we will likewise be able to specify a small set of detailed vegetation covariates, e.g., tree species, canopy age, and patch configuration. Combinations of the two covariate sets will then be used to define a priori models for evaluation. This will greatly simplify the daunting task of variable selection for complex hierarchical models. 
Fig. 5. The spatial distribution of Black-throated Green Warbler observations in the project database, as of 25 February 2009.

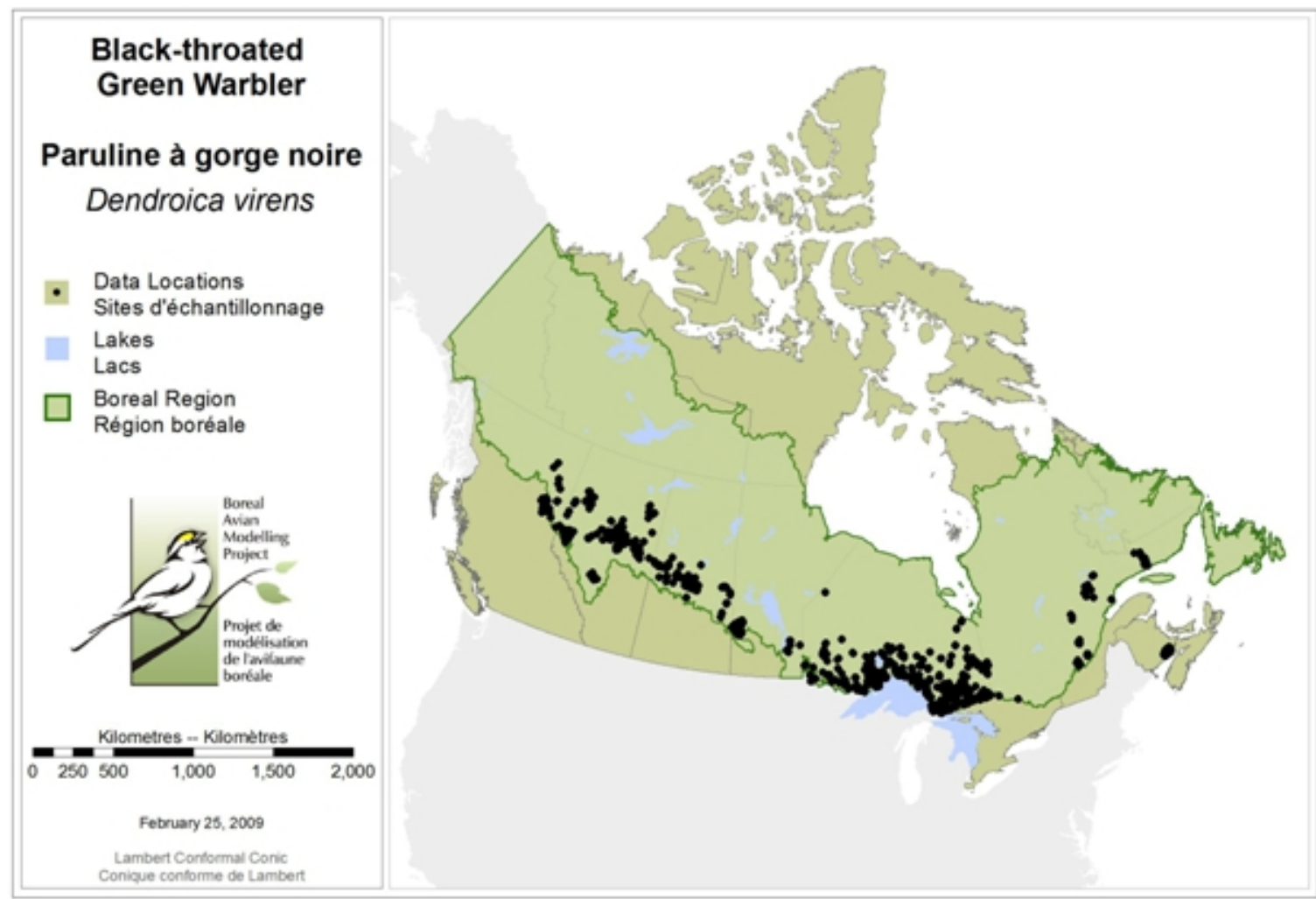

THE PATH FORWARD: LINKING SCIENCE AND MANAGEMENT

The Boreal Avian Modelling Project's national database is enabling the development of spatially explicit, habitat-based predictive models of bird distributions that will be broadly accessible. We welcome participation by other contributors. Improved coverage in poorly sampled areas (Fig. 3) or years (Fig. 4) and datasets that could calibrate detectability functions and density estimates, e.g., spot-mapping data, would be especially helpful. The project database, online documentation, and website will be updated regularly as new information becomes available. However, databases, models, and our scientific enquiries are not ends in themselves. We now discuss some of their intended applications to conservation planning, forest management planning, and monitoring initiatives.

Predictive models of species abundances and population sizes in relation to vegetation, land use intensity, and climate will contribute to strategic planning for the conservation of migratory birds. One noted example is the completion of Bird Conservation Region Plans throughout boreal Canada, which will identify priority species and associated population objectives, and define and prioritize conservation actions. For species at risk, our findings should improve the accuracy of status assessments for boreal land birds. For environmental assessments, our models can assist in estimating the individual and cumulative impact of industrial activity on boreal land birds. Our models will support the management of incidental take under the MBCA. From models of effects of industrial activity, we will be able to estimate the magnitude and effects of incidental take on birds in the boreal forest. This will inform the development of Best Management Practices and Guidelines that mitigate and offset such effects to support conservation of migratory bird populations.

Our models will also contribute to the companion Canadian BEACONs project that is developing 
Fig. 6. The structure of the CART model for the Black-throated Green Warbler. The model recursively partitions the observations into groups (or "terminal nodes") such that the proportion of total deviance attributable to between-group differences is maximized, subject to parsimony constraints. The model covariates are defined in the text. The "main split" is the test "September NDVI < 0.680 " which partitions the data into a left subtree where the condition holds, and a right subtree where it does not. The left subtree is partitioned further into three terminal nodes, each with low mean abundance (Mean) and high prediction reliability (Reliability, explained in the text). Within the right subtree, terminal node 7 has the highest mean abundance at 0.938 individuals per standardized point-count. It is defined as those locations with September NDVI $\geq 0.68$, Seasonality < 4.284, and standard deviation of mean total July precipitation $<39.423$. The numerical values of the decision criteria, group means, and reliability indices are bootstrap estimates. The covariates are defined in the text.

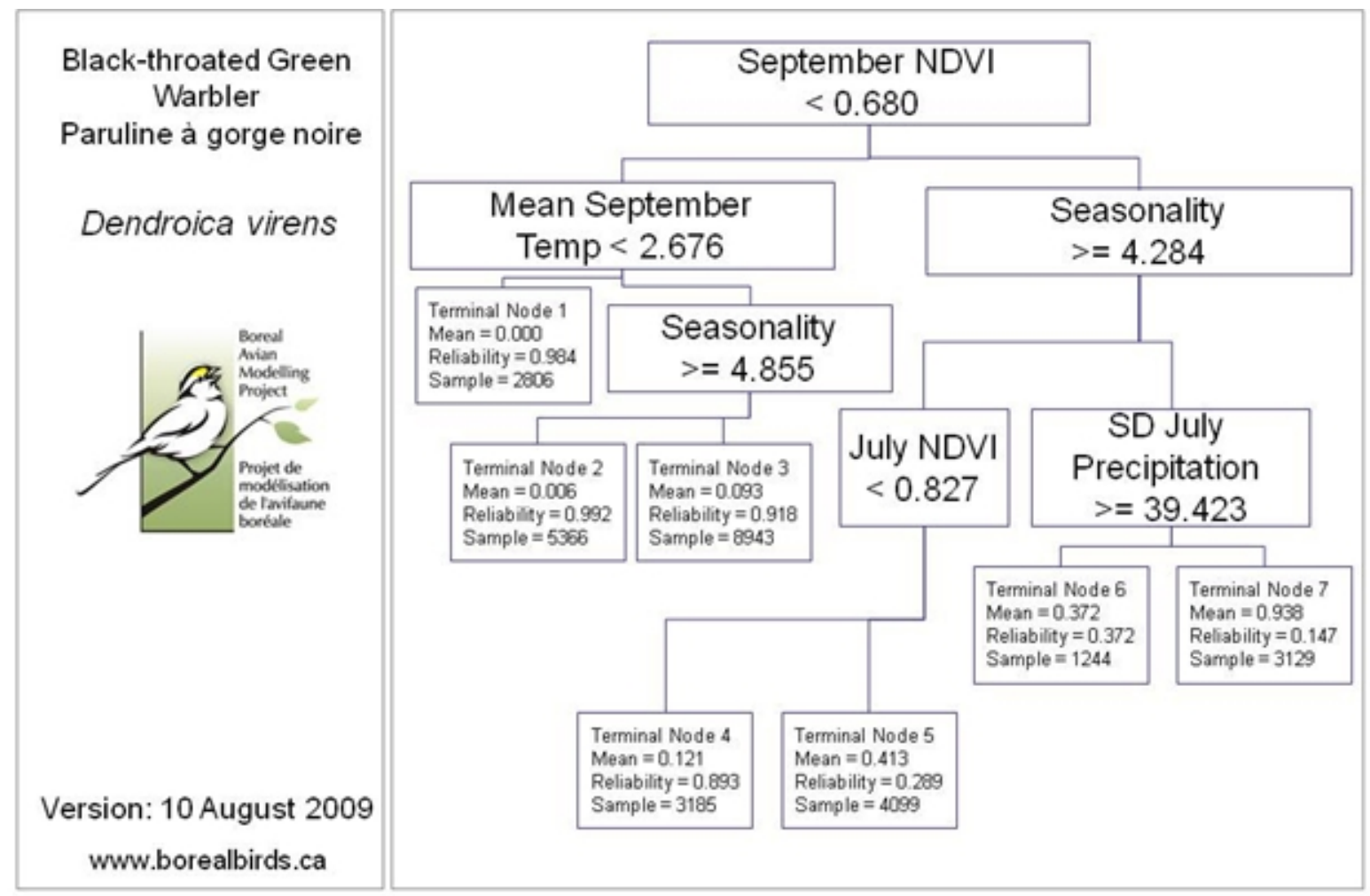

methodologies for systematic conservation planning across the Canadian boreal forest. The cornerstone of BEACONs' approach (Leroux et al. 2007a,b) is a set of ecological criteria for defining and mapping potential systems of ecological benchmarks. The predictive species abundance maps produced by BAM represent a major advance useful for this purpose compared to the more general, biophysical criteria typically used to select candidate areas for protection.

To the extent that any forest songbird species requires large contiguous patches of post-rotation age forest, forest management practices will have far-reaching effects on their populations. Canada contains 402 million hectares of forested land (Natural Resources Canada 2009), of which 163 million ha $(40.5 \%)$ is allocated to forest management under some form of tenure. Most of this activity is concentrated in the most productive areas in the southern boreal region and within these tenures, harvesting selectively targets older stands of commercially valuable species. Many forest products companies seek to include avian habitat quality in their detailed forest management plans, using spatial simulation models and scenario 
Fig. 7. Mapped predicted abundances of Black-throated Green Warbler according to the model of Figure 6 . The seven terminal nodes of the CART model and their corresponding estimated mean abundances are shown in the legend. The half-tone screen partially masks areas where little or no data are available (Fig. 3). Note that predictions cover only the boreal and taiga regions as defined in Fig. 3; some regions, such as New Brunswick, where Boreal Avian Modelling Project data exist have therefore been excluded for now.

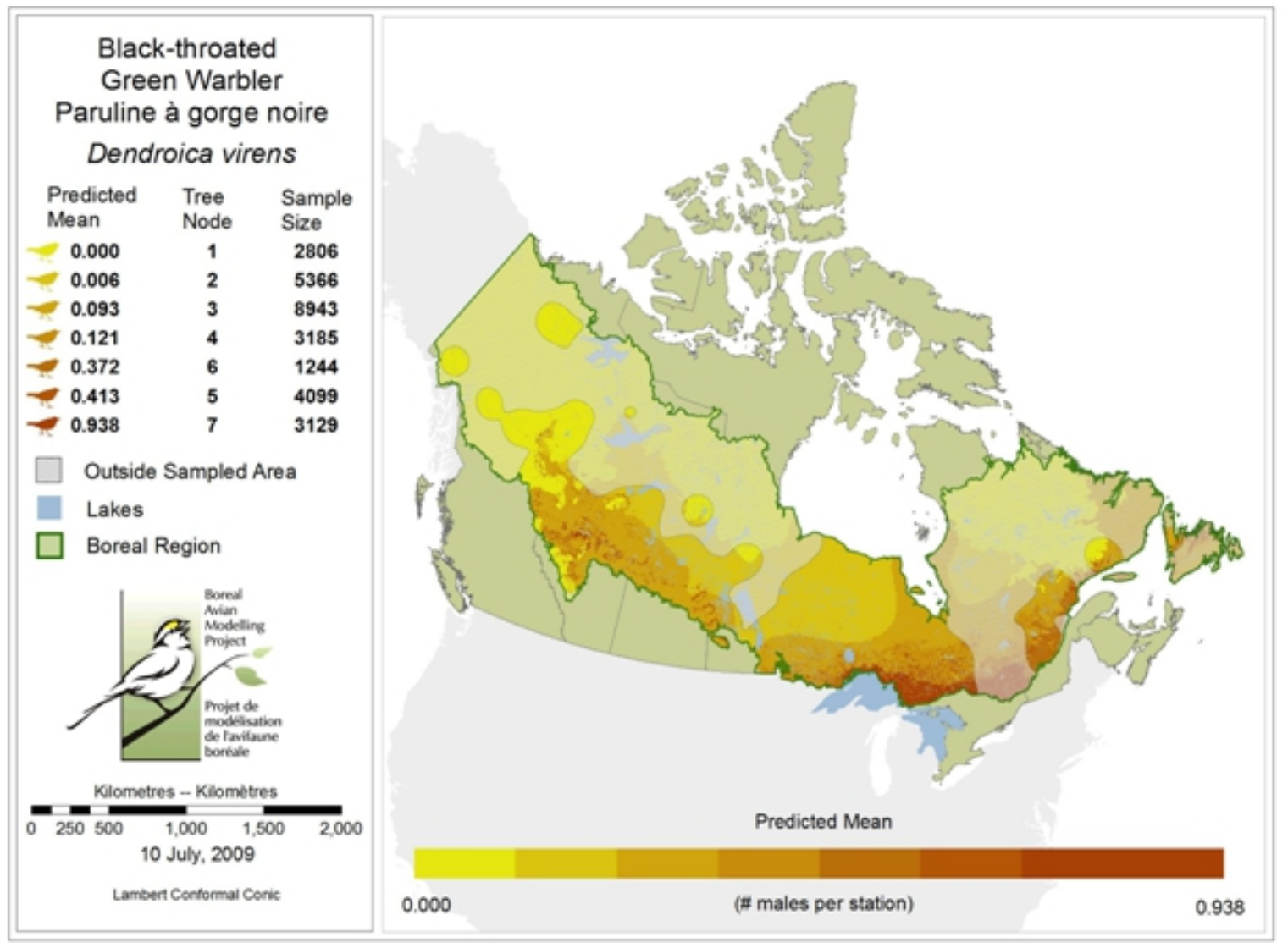

analysis to assess outcomes and design strategies for bird population maintenance (e.g., Rempel et al. 2007). Our national initiative could be broadly useful in that regard, such as when firms responded to the proposed amendments to Migratory Birds Regulations as mentioned earlier. To meet this potential, our models need to link management actions with ecological indicators, e.g., habitat supply, population size.

Forest management planning tools rely on attributes contained in Forest Resource Inventory (FRI) data, such as canopy age, height and species composition; characteristics that are also useful for modeling avian habitat and abundance both locally and regionally (Betts et al. 2006, Rempel et al. 2007, Vernier et al. 2008). These attributes are not derivable from remote-sensed land cover products currently available at national extents. In response to this, we have assembled almost all extant Canadian FRI data and converted them to a standardized data format (Cumming et al. 2010b). All the information contained in the source data is preserved. By including more detail about the age, tree species, and spatial configuration of forest habitats, we expect to be able to address many of the limitations of our first generation models, e.g., low prediction reliabilities of the Black-throated Green Warbler CART model, in a consistent and comparable manner across Canada's managed 
Fig. 8. Estimated prediction reliabilities of the seven terminal nodes in the CART model for Blackthroated GreenWarbler (Fig. 6). The half-tone screen partially masks areas where little or no data are available. Note that this map covers only the boreal and taiga regions as defined in Fig. 3; some regions, such as New Brunswick, where Boreal Avian Modelling Project data exist have therefore been excluded for now.

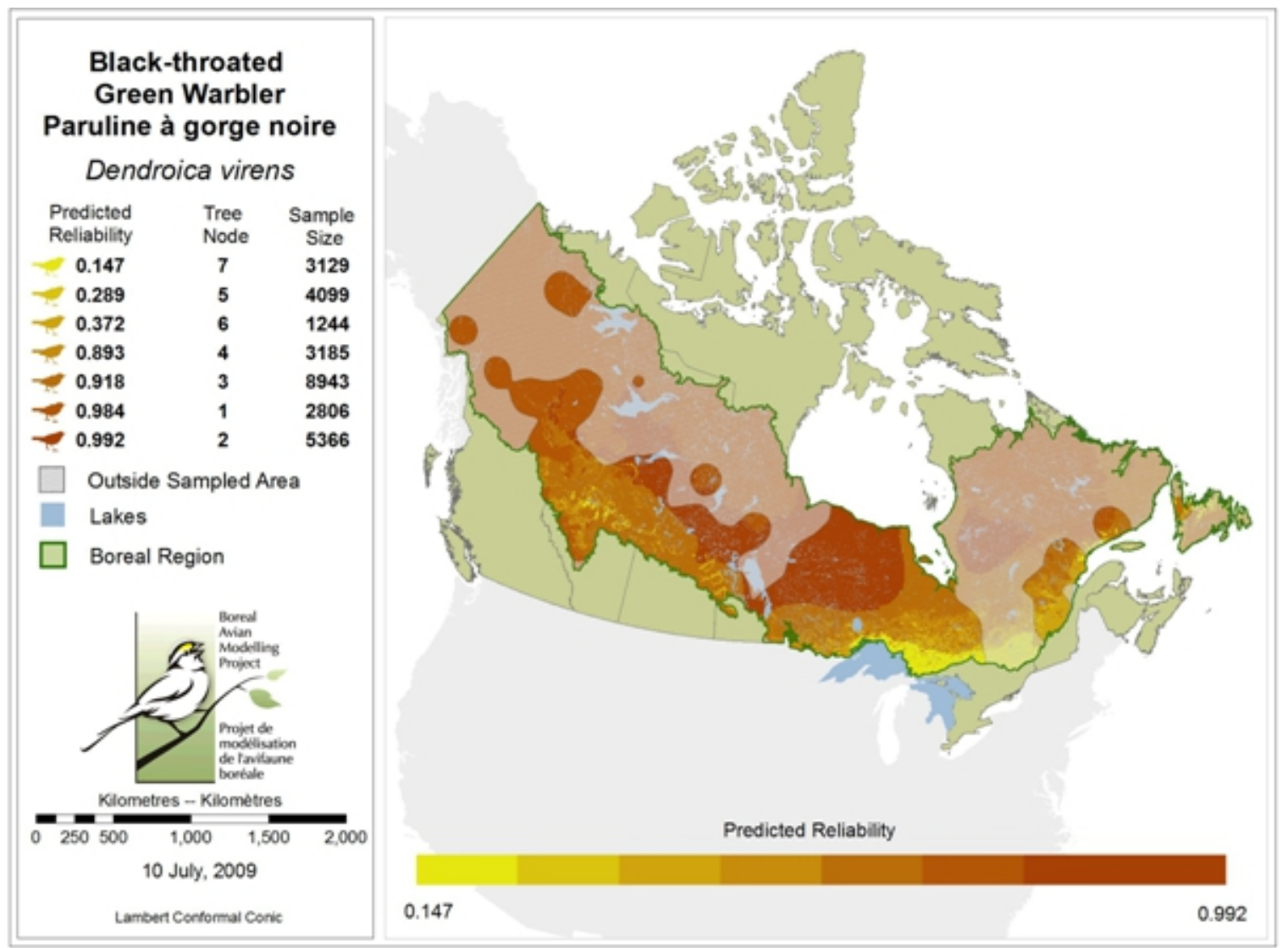

boreal forests. The FRI will also provide the spatial extent and thematic precision necessary to assess the consistency of habitat selection across the region, especially for species such as the Canada Warbler (Wilsonia canadensis) and Connecticut Warbler (Oporornis agilis) for which marked geographic variation have been reported (Pitocchelli et al. 1997, Reitsma et al. 2010). This land cover product will be broadly relevant for predicting the impact of other large-scale land use activities in the boreal forest, such as energy and mining, and the cumulative effect of these various human activities on migratory bird populations.

The skeptical reader may now ask, "What will be the use of BAM's models in the long term, given that land use patterns and climate may change?" Our answer is simple. The entire point of this effort is to be able to predict species responses to such changes should they eventuate. These predictions can be obtained by applying to the models the appropriate combinations of covariates that describe the anticipated changes, e.g., of future climate. The results represent hypotheses that can be tested by collecting new data. Uncertainties arising from the spatially unbalanced sample design (Fig. 3) may be addressed in the same way. In a generalized linear regression framework, model predictions at new data locations have prediction errors which can be estimated by standard techniques. Methods exist for identifying informative locations to collect further data given the estimated prediction errors. By 
mapping expected information gain in relation to road networks and other means of access, one could identify cost effective locations for acquiring data likely to test and improve the models. This is known as (sequential) "model-based design" (Särndal 1978).

The previous remarks point to the formal links between statistical modeling, monitoring, and management. Efforts to compensate for incidental take or to adapt forest management plans to minimize habitat loss and population declines rely on predictive applications of models: "treatment $x$ will result in indicator level $y$." In all cases, these predictions must be verified by monitoring in treated areas and controls, and strategies must be adjusted as new knowledge is gained. The monitoring step collects additional data that can be used to improve the statistical models, resulting in more reliable predictions. This is the essence of adaptive management (Walters and Hilborn 1978, Walters and Holling 1990). Adaptive management will be vital to the conservation of Canada's boreal birds, because we cannot yet reliably predict the outcomes of the extensive experiments now underway.

Although BAM is positioned to make a significant contribution to monitoring, it is not itself a monitoring program. In fact, no comprehensive national monitoring program designed for boreal birds now exists. Such a program is necessary, however, if Canada is to fulfill national and international obligations to manage migratory bird populations (Cooke 2003, Rich et al. 2004). Comprehensive monitoring would address the spatial limitations of existing data and provide better measurements of the principal threats to boreal bird populations such as habitat loss and alteration (Hobson et al. 2002, Schmiegelow and Monkkonen 2002). The vastness and inaccessibility of unsampled areas (e.g., Fig.3) require that any such program be carefully designed. Methods of modelbased survey design should be applied to identify relatively accessible yet maximally informative areas for targeted sampling in remote regions and to monitoring outcomes of management actions in more accessible areas.

We welcome collaborations with researchers, forest products firms, government agencies, conservation organizations, and any other entities with interest in or responsibilities for avian conservation in boreal
Canada. Only through our collective efforts will the bountiful avifauna of Canada's boreal regions continue to provide the ecological services and the esthetic and intellectual inspirations we currently enjoy.

Responses to this article can be read online at: http://www.ace-eco.org/vol5/iss2/art8/responses/

\section{Acknowledgments:}

The authors are grateful for the contributions of many funding agencies, members of the project Technical Committee, collaborators and data partners from across Canada, and past members of the project team.

We thank Peter Lee and Global Forest Watch Canada for provided images for this manuscript.

The Boreal Avian Modelling Project has received financial support from: Environment Canada, US Fish and Wildlife Service's Neotropical Migratory Bird Conservation Act Grants Program, Alberta Research Council, Canada Foundation for Innovation, Canada Research Chairs program, Canadian Boreal Initiative, Ducks Unlimited Canada, Environmental Studies Research Fund, Fonds québécois de la recherche sur la nature et les technologies, Forest Products Association of Canada, Natural Sciences and Engineering Research Council of Canada, Sustainable Forest Management Network, the GEOIDE Network, Université Laval, and University of Alberta. In-kind support is provided by the Boreal Ecosystems Analysis of Conservation Networks (BEACONs) Project.

We gratefully acknowledge the support and counsel of our Technical Committee:

Peter Blancher (Environment Canada); Marcel Darveau (Ducks Unlimited Canada/Université Laval); Jean-Luc DesGranges (Environment Canada); André Desrochers (Université Laval); Andrew de Vries (Forest Products Association of Canada); Pierre Drapeau (Université du Québec à Montréal); Charles Francis (Environment Canada); Keith Hobson (Environment Canada); Craig Machtans (Environment Canada); Julienne Morissette (Ducks Unlimited Canada); Rob Rempel (Ontario Ministry of Natural Resources); Stuart 
Slattery (Ducks Unlimited Canada); Phil Taylor (Acadia University); Steve Van Wilgenburg (Environment Canada); Lisa Venier (Canadian Forest Service); Pierre Vernier (University of British Columbia); Marc-André Villard (Université de Moncton).

We thank past team members Dan Mazerolle and Shoufan Fang for their invaluable contributions. We also thank the following individuals for their assistance: Melanie-Louise Leblanc, Mélina Houde, Pierre Racine, and Bénédicte Kenmei (Université Laval); Lisa Mahon and Kim Lisgo (University of Alberta); Pierre Vernier (University of British Columbia); Stephanie Topp, Zhong Li, and Kevin Hannah (Environment Canada); Sheila MacLeodPotter(Blue Chair Designs); Paul Morrill (Web Services); and Gido Langen and John Cosco (Timberline Natural Resource Group).

Finally, we thank the following institutions and individual researchers whose generous data contributions have made the project possible.

Institutions: Acadia University, Alberta Biodiversity Monitoring Institute, Alberta Pacific Forest Industries Inc., Alberta Research Council Inc., AMEC Earth \& Environmental, AREVA Resources Canada Inc., AXYS Environmental Consulting Ltd., Bighorn Wildlife Technologies Ltd., Bird Studies Canada, Canadian Natural Resources Ltd., Canfor Corporation, Daishowa Marubeni International Ltd, Ducks Unlimited Canada, Environment Canada / Canadian Wildlife Service, Forest Products Association of Canada, Global Landcover Facility, Golder Associates Ltd., Government of British Columbia, Government of Ontario, Government of Saskatchewan, Government of Yukon, Hinton Wood Products, Hydro-Québec Équipement, Kluane Ecosystem Monitoring Project, Komex International Ltd., Louisiana Pacific Canada Ltd., Manitoba Hydro, Manitoba Model Forest Inc., Manning Diversified Forest Products Ltd., Matrix Solutions Inc., MEG Energy Corp., Mirkwood Ecological Consultants Ltd., Natural Resources Canada / Canadian Forest Service, Numerical Terradynamic Simulation Group, Ontario Ministry of Natural Resources, OPTI Canada Inc., PanCanadian Petroleum Limited, Petro Canada, Principal Wildlife Resource Consulting, Rio Alto Resources International Inc., Shell Canada Limited, Suncor Energy Inc., Tembec Industries Inc., Tolko Industries Ltd., Université du Québec à Montréal, Université du Québec en
Abitibi-Témiscamingue, Université Laval, University of Alberta, University of British Columbia, University of Guelph, University of New Brunswick, University of Northern British Columbia, URSUS Ecosystem Management Ltd., West Fraser Timber Co. Ltd., Weyerhaeuser Company Ltd., Wildlife Resource Consulting Services MB Inc.

Individuals: J. Ball, E. Bayne, P. Belagus, S. Bennett, R. Berger, M. Betts. J. Bielech, A. Bismanis, R. Brown, M. Cadman, D. Collister, M. Cranny, S. Cumming, L. Darling, C. De La Mare, A. Desrochers, T. Diamond, M. Donnelly, M. Drapeau, C. Duane, B. Dube, D. Dye, R. Eccles, P. Farrington, R. Fernandes, D. Fortin, K. Foster, M. Gill, R. Hall, S. Hannon, B. Harrison, J. Herbers, L. Imbeau, P. Johnstone, $V$. Keenan, $S$. Lapointe, $R$. Latifovic, $R$. Lauzon, M. Leblanc, L. Ledrew, J. Lemaitre, D. Lepage, B. MacCallum, P. MacDonell, C. Machtans, L. Margantini, S. Mason, M. McGovern, D. McKenney, T. Nudds, P. Papadopol, M. Phinney, D. Phoenix, D. Pinaud, D. Player, D. Price, R. Rempel, A. Rosaasen, S. Running, R. Russell, $C$. Savingnac, J. Schieck, F. Schmiegelow, P. Sinclair, A. Smith, S. Song, C. Spytz, P. Taylor, S. Van Wilgenburg, P. Vernier, D. Whitaker, J. Witiw, S. Wyshynski, M. Yaremko.

\section{LITERATURE CITED}

Alldredge, M. W., T. R. Simons, and K. H. Pollock. 2007. Factors affecting aural detections of songbirds. Ecological Applications 17:948-955.

Anderson, S. H. 1981. Correlating habitat variables and birds. In C. J. Ralph, and J. M. Scott, editors. Estimating numbers of terrestrial birds. Studies in avian biology Number 6. Allen Press, Lawrence, Kansas, USA.

Austin, M. 2007. Species distribution models and ecological theory: a critical assessment and some possible new approaches. Ecological Modelling 200:1-19.

Bayne, E. M., and K. A. Hobson. 2002. Apparent survival of male ovenbirds in fragmented and forested boreal landscapes. Ecology 83:1307-1316.

Betts, M. G., A. W. Diamond, G. J. Forbes, M. A. Villard, and J. S. Gunn. 2006. The importance of 
spatial autocorrelation, extent and resolution in predicting forest bird occurrence. Ecological Modelling 191:197-224.

Berlanga, H., J. A. Kennedy, T. D. Rich, M. C. Arizmendi, C. J. Beardmore, P. J. Blancher, G. S. Butcher, A. R. Couturier, A. A. Dayer, D. W. Demarest, W. E. Easton, M. Gustafson, E. IñigoElias, E. A. Krebs, A. O. Panjabi, V. Rodriguez Contreras, K. V. Rosenberg, J. M. Ruth, E. Santana Castellón, R. Ma. Vidal, and T. Will. 2010. Saving our shared birds: partners in flight trinational vision for landbird conservation. Cornell Lab of Ornithology, Ithaca, New York, USA. [online] URL: http://www.savingoursharedbirds.org/ final reports pdfs/PIF2010 English Final.pdf.

Blancher, P. 2003. The importance of Canada's borealforest to landbirds. Bird Studies Canada, Port Rowan, Ontario, Canada.

Blancher, P. J., K. V. Rosenberg, A. O. Panjabi, B. Altman, J. Bart, C. J. Beardmore, G. S. Butcher, D. Demarest, R. Dettmers, E. H. Dunn, W. Easton, W. C. Hunter, E. E. Iñigo-Elias, D. N. Pashley, C. J. Ralph, T. D. Rich, C. M. Rustay, J. M. Ruth, and T. C. Will. 2007. Guide to the Partners in Flight Population Estimates Database. Version: North American Landbird Conservation Plan 2004. Partners in Flight Technical Series Number 5. [online] URL: http://rmbo.org/pif db/la ped/download/Guide\%20to\%20PIF\%20Population\% 20Estimates\%20Database\%202.pdf.

Buckland, S. T., D. R. Anderson, K. P. Burnham, J. L. Laake, D. L. Borchers, and L. Thomas. 2001. Introduction of distance sampling: estimating abundance of biological populations. Oxford University Press, Oxford, UK.

Buermann, W., S. Saatchi, T. B. Smith, B. R. Zutta, J. A. Chaves, B. Milá, and C. H. Graham. 2008. Predicting species distributions across the Amazonian and Andean regions using remote sensing data. Journal of Biogeography 35:1160-1176.

Carlson, M., and F. Schmiegelow. 2002. Costeffective sampling design applied to large-scale monitoring of boreal birds. Conservation Ecology 6:18.

Cody, M. L., editor. 1985. Habitat selection in birds. Academic Press, New York, New York, USA.
Cooke, F. 2003. Ornithology and bird conservation in North America - a Canadian perspective. Bird Study 50:211-222.

Cumming, E. E., K. A. Hobson, and S. L. Van Wilgenburg. 2001. Breeding bird declines in the boreal forest fringe of western Canada: insights from long-term BBS routes. Canadian FieldNaturalist 115:425-435.

Cumming, S. G., and M. Leblanc. 2010a. The Boreal Avian Modelling Project Biophysical Dataset. Part 1: Catalogue and Descriptive Statistics. [online] URL: http://www.borealbirds.ca/ library/index.php/technical reports.

Cumming, S. G., and M. Leblanc. 2010b. The Boreal Avian Modelling Project Biophysical Dataset. Part 2: Population and Sample Distributions. [online] URL: http://www.borealbirds. ca/library/index.php/technical reports.

Cumming, S. G., K. Lefevre, and M. Leblanc. 2010a. The Boreal Avian Modelling Project Avian Dataset: Structure and Descriptive Statistics. [online] URL: http://www.borealbirds.ca/library/index. php/technical reports.

Cumming, S. G., F. K. A. Schmiegelow, E. M. Bayne, and S. J. Song. 2010b. Canada's forest resource inventories: compiling a tool for boreal ecosystems analysis and modelling-a background document. Version 1.0 7 January 2010. [online] URL: http://www.borealbirds.ca/files/technical reports/ CAS Backgrounder v1.0.pdf.

De'ath, G., and K. E. Fabricius. 2000. Classification and regression trees: a powerful yet simple technique for ecological data analysis. Ecology 81:3178-3192.

Devictor, V., R. Julliard, D. Couvet, and F. Jiguet. 2008. Birds are tracking climate warming, but not fast enough. Proceedings of the Royal Society BBiological Sciences 275(1652):2743-2748.

Donovan, T. M., C. J. Beardmore, D. N. Bonter, J. D. Brawn, R. J. Cooper, J. A. Fitzgerald, R. Ford, S. A. Gauthreaux, T. L. George, W. C. Hunter, T. E. Martin, J. Price, K. V. Rosenberg, P. D. Vickery, and T. B. Wigley. 2002. Priority research needs for the conservation of neotropical migrant landbirds. Journal of Field Ornithology 73:329-339. 
Drapeau, P., A. Leduc, J.-F. Giroux, J.-P. L. Savard, Y. Bergeron, and W. L. Vickery. 2000. Landscape-scale disturbances and changes in bird communities of boreal mixed-wood forests. Ecological Monographs 70:423-444.

Environment Canada. 2010. Bird Conservation Region Plans and Incidental Take. Canadian Wildlife Service national website. [online] URL: http://www.ec.gc.ca/paom-itmb/default.asp?lang= En\&n=3BA633AC-1.

Fauth, P. T., E. J. Gustafson, and K. N. Rabenold. 2000. Using landscape metrics to model source habitat for neotropical migrants in the midwestern US. Landscape Ecology 15:621-631.

Fearer, T. M., S. P. Prisley, D. F. Stauffer, and P. D. Keyser. 2007. A method for integrating the Breeding Bird Survey and Forest Inventory and Analysis databases to evaluate forest bird-habitat relationships at multiple spatial scales. Forest Ecology and Management 243:128-143.

Flather, C. H., and J. R. Sauer. 1996. Using landscape ecology to test hypotheses about largescale abundance patterns in migratory birds. Ecology 77:28-35.

Forcey, G. M., G. M. Linz, W. E. Thogmartin, and W. J. Bleier. 2007. Influence of land use and climate on wetland breeding birds in the Prairie Pothole region of Canada. Canadian Journal of Zoology 85:421-436.

Freemark, K. E., J. B. Dunning, S. J. Hejl, and J. R. Probst. 1995. A landscape ecology perspective for research, conservation, and management. Pages 381-421 in T. E. Martin, and D. M. Finch, editors. Ecology and management of neotropical migratory birds: a synthesis and review of critical issues. Oxford University Press, New York, New York, USA.

Gates, S., D. W. Gibbons, P. C. Lack, and R. J. Fuller. 1994. Declining farmland bird species: modelling geographical patterns of abundance in Britain. Pages 153-178 in P. J. Edwards, R. M. May, and N. R. Webb, editors. Large-scale ecology and conservation biology. Blackwell Science, Oxford, UK.
Gottschalk, T. K., F. Huettmann, and M. Ehlers. 2005. Thirty years of analysing and modelling avian habitat relationships using satellite imagery data: a review. International Journal of Remote Sensing 26:2631-2656.

Gregory, R. D., and K. J. Gaston. 2000. Explanations of commonness and rarity in British breeding birds: separating resource use and resource availability. Oikos 88:515-526.

Guisan, A., and N. E. Zimmermann. 2000. Predictive habitat distribution models in ecology. Ecological Modelling 135:147-186.

Hansson, L. 1992. Landscape ecology of boreal forests. Trends in Ecology \& Evolution 7:299-302.

Heikkinen, R. K., M. Luoto, R. Virkkala, and K. Rainio. 2004. Effects of habitat cover, landscape structure and spatial variables on the abundance of birds in an agricultural-forest mosaic. Journal of Applied Ecology 41:824-835.

Hobson, K. A., and E. Bayne. 2000. Breeding bird communities in boreal forest of western Canada: Consequences of "unmixing" the mixedwoods. Condor 102:759-769.

Hobson, K. A., E. M. Bayne, and S. L. Van Wilgenburg. 2002. Large-scale conversion of forest to agriculture in the boreal plains of Saskatchewan. Conservation Biology 16:1530-1541.

Jones, J. 2001. Habitat selection studies in avian ecology: a critical review. Auk 118:557-562.

Kerr, J. T., H. M. Kharouba, and D. J. Currie. 2007. The macroecological contribution to global change solutions. Science 316:1581-1584.

Kuhnert, P., and K. Mengersen. 2003. Reliability measures for local nodes assessment in classification trees. Journal of Computational and Graphical Statistics 12:398-416.

Krawchuk, M. A., S. G. Cumming, M. D. Flannigan, and R. W. Wein. 2006. Biotic and abiotic regulation of lightning fire initiation in the mixedwood boreal forest. Ecology 87:458-468.

Latifovic, R., I. Olthof, D. Pouliot, and J. Beaubien. 2008. Land cover map of Canada 2005 
at $250 \mathrm{~m}$ spatial resolution. Natural Resources Canada/ESS/Canada Centre for Remote Sensing. ftp://ftp.ccrs.nrcan.gc.ca/ad/NLCCLandCover/ LandcoverCanada2005 250m/.

Lee, P., D. Aksenov, L. Laestadius, R. Nogueron, and W. Smith. 2003. Canada's large intact forest landscapes. Global Forest Watch Canada, Edmonton, Alberta, Canada.

Leroux, S. J., F. K. A. Schmiegelow, S. G. Cumming, R. B. Lessard, and J. Nagy. $2007 a$. Accounting for system dynamics in reserve design. Ecological Applications 17:1954-1966.

Leroux, S. J., F. K. A. Schmiegelow, R. B. Lessard, and S. G. Cumming. 2007b. Minimum dynamic reserves: a framework for determining reserve size in ecosystems structured by large disturbances. Biological Conservation 138:464-473.

Lichstein, J. W., T. R. Simons, and K. E. Franzreb. 2002. Landscape effects on breeding songbird abundance in managed forests. Ecological Applications 12:836-857.

Luoto, M., R. Virkkala, R. K. Heikkinen, and K. Rainio. 2004. Predicting bird species richness using remote sensing in boreal agricultural-forest mosaics. Ecological Applications 14:1946-1962.

Natural Resources Canada. 2009. The state of Canada's forests: annual report 2009. Natural Resources Canada, Ottawa, Ontario, Canada. [online] URL: http://www.canadaforests.nrcan.gc.ca

Machtans, C. S. 2006. Songbird response to seismic lines in the western boreal forest: a manipulative experiment. Canadian Journal of Zoology-Revue Canadienne De Zoologie 84:1421-1430.

Martin, T. G., I. Chade, P. Arcese, P. P. Marra, H. P. Possingham, and D. R. Norris. 2007. Optimal conservation of migratory species. PLoS ONE 2(8):e751.

North American Bird Conservation Initiative (NABCI). 2000. Bird conservation region descriptions. United States Fish and Wildlife Service. Arlington, Virginia, USA. [online] URL: http://www.nabci-us.org/aboutnabci/bcrdescrip.pdf
Ostlund, L., O. Zackrisson, and A. L. Axelsson. 1997. The history and transformation of a Scandinavian boreal forest landscape since the 19th century. Canadian Journal of Forest Research 27:1198-1206.

Peters, D. C. P., P. M. Groffman, K. J. Nadelhoffer, N. B. Grimm, S. L. Collins, W. K. Michener, and M. A. Huston. 2008. Living in an increasingly connected world: a framework for continental-scale environmental science. Frontiers in Ecology and Environment 6:229-237.

Pitocchelli, J., J. Bouchie, and D. Jones. 1997. Connecticut Warbler (Oporornis agilis). From A. Poole, editor. The birds of North America online. Cornell Lab of Ornithology, Ithaca, New York, USA. [online] URL: http://bna.birds.cornell.edu/bna/ species/320.

Rahbek, C., N. J. Gotelli, R. K. Colwell, G. L. Entsminger, T. Rangel, and G. R. Graves. 2007. Predicting continental-scale patterns of bird species richness with spatially explicit models. Proceedings of the Royal Society B-Biological Sciences 274:165-174.

Ralph, C. J., J. R. Sauer, and S. Droege, editors. 1995. Monitoring bird populations by point counts. General Technical Report PSW-GTR-149 edition. Pacific Southwest Research Station, Forest Service, United States Department of Agriculture, Albany, California, USA.

Reitsma, L., M. Goodnow, M. T. Hallworth, and C. J. Conway. 2010. Canada Warbler (Wilsonia canadensis). From A. Poole, editor. The birds of North America online. Cornell Lab of Ornithology, Ithaca, New York, USA. [online] URL: http://bna.b irds.cornell.edu/bna/species/421/articles/introduction

Rempel, R. S., J. Baker, P. C. Elkie, M. J. Gluck, J. Jackson, R. S. Kushneriuk, T. Moore, and A. H. Perera. 2007. Forest policy scenario analysis: sensitivity of songbird community to changes in forest cover amount and configuration. Avian Conservation and Ecology - Écologie et conservation des oiseaux 2(1): 5. [online] URL: http://www.ace-eco.org/vol2/iss1/art5/.

Rich, T. D., C. J. Beardmore, H. Berlanga, P. J. Blancher, M. S. W. Bradstreet, G. S. Butcher, D. W. Demarest, E. H. Dunn, W. C. Hunter, E. E. 
Iñigo-Elias, J. A. Kennedy, A. M. Martell, A. O. Panjabi, D. N. Pashley, K. V. Rosenberg, C. M. Rustay, J.S. Wendt, and T. C. Will. 2004. Partners in Flight North American Landbird Conservation Plan. Cornell Lab of Ornithology, Ithaca, New York, USA.

Roca, R., L. Adkins, M. C. Wurschy, and K. Skerl. 1996. Transboundary conservation: an ecoregional approach to protect neotropical migratory birds in South America. Environmental Management 20:849-863.

Royle, J. A., M. Kéry, R. Gautier, and H. Schmid. 2007. Hierarchical spatial models of abundance and occurrence from imperfect survey data. Ecological Monographs 77:465-481.

Rushton, S. P., S. J. Ormerod, and G. Kerby. 2004. New paradigms for modelling species distributions? Journal of Applied Ecology 41:193-200.

Särndal, C.-E. 1978. Design-based and modelbased inference in survey sampling. Scandinavian Journal of Statistics 5:27-52.

Schieck, J., and S. J. Song. 2006. Changes in bird communities throughout succession following fire and harvest in boreal forests of western North America: literature review and meta-analyses. Canadian Journal of Forest Research 36:1299-1318.

Schmiegelow, F. K. A., C. S. Machtans, and S. J. Hannon. 1997. Are boreal birds resilient to forest fragmentation? An experimental study of shortterm community responses. Ecology 78:1914-1932.

Schmiegelow, F. K.A., and M. Monkkonen. 2002. Habitat loss and fragmentation in dynamic landscapes: avian perspectives from the boreal forest. Ecological Applications 12:375-389.

Schneider, R. R., J. B. Stelfox, S. Boutin, and S. Wasel. 2003. Managing the cumulative impacts of land uses in the Western Canadian Sedimentary Basin: a modeling approach. Conservation Ecology 7:11.

Thogmartin, W. E., and M. G. Knutson. 2007. Scaling local species-habitat relations to the larger landscape with a hierarchical spatial count model. Landscape Ecology 22:61-75.
Thompson, W. L. 2002. Towards reliable bird surveys: accounting for individuals present but not detected. Auk 119:18-25.

Thuiller, W., M. B. Araujo, and S. Lavorel. 2004. Do we need land-cover data to model species distributions in Europe? Journal of Biogeography 31:353-361.

Toms, J. D., F. K. A. Schmiegelow, S. J. Hannon, and M.A. Villard. 2006. Are point counts of boreal songbirds reliable proxies for more intensive abundance estimators? Auk 123:438-454.

Urban, D. L., and T. M. Smith. 1989. Microhabitat pattern and the structure of forest bird communities. American Naturalist 133:811-829.

Venier, L. A., and J. L. Pearce. 2007. Boreal forest landbirds in relation to forest composition, structure, and landscape: implications for forest management. Canadian Journal of Forest Research-Revue Canadienne De Recherche Forestière 37:1214-1226.

Venier, L. A., J. Pearce, J. E. McKee, D. W. McKenney, and G. J. Niemi. 2004. Climate and satellite-derived land cover for predicting breeding bird distribution in the Great Lakes Basin. Journal of Biogeography 31:315-331.

Vernier, P. R., F. K. A. Schmiegelow, S. Hannon, and S. G. Cumming. 2008. Generalizability of songbird habitat models in boreal mixedwood forests of Alberta. Ecological Modelling 211:191-201.

Walters, C. J., and R. Hilborn. 1978. Ecological optimization and adaptive management. Annual Review of Ecology and Systematics 9:157-188.

Walters, C. J., and C. S. Holling. 1990. Largescale management experiments and learning by doing. Ecology 71:2060-2068.

Webster, M., P. Marra, S. Haig, S. Bensch, and R. Holmes. 2002. Links between worlds: unraveling migratory connectivity. Trends in Ecology \& Evolution 17:76-83.

Willson, M. F. 1974. Avian community organization and habitat structure. Ecology 55:1017-1029. 